\title{
Designação e reescritura em textos de divulgação científica
}

\author{
Maria Elizete Melo de Oliveira (UFMA)* \\ https://orcid.org/0000-0003-2083-9236 \\ Leonildes Lima Colaço Teixeira de Arêa Leão (UFMA)** \\ https://orcid.org/0000-0002-4657-3635 \\ Paulo da Silva Lima (UFMA)*** \\ https://orcid.org/0000-0002-3270-6353
}

\section{Resumo:}

Este artigo objetiva analisar os processos de designação e reescritura em textos de divulgação científica destinado ao público infantil a partir da Semântica da Enunciação, partindo da premissa de que o sentido dos enunciados está inserido no acontecimento da enunciação. Para isso, tomamos por base teórica Guimarães (2009, 2014, 2018), Machado (2019) e Silva (2019). Discutimos a proposta tomando como corpus textos de divulgação científica retirados da versão on-line da revista Ciência Hoje das Crianças (CHC), nos quais analisamos os processos de designação e reescritura e o modo que atuam na construção dos sentidos dos enunciados. Diante disso, pudemos constatar que a designação e a reescritura estabelecem relações de sentido na construção dos textos permitindo aos interlocutores participarem do acontecimento enunciativo por meio da compreensão dos enunciados.

Palavras-Chave: Semântica da Enunciação; Designação; Reescritura; Divulgação Científica.

\section{Abstract: \\ Designation and rewriting in scientific dissemination texts}

This article aims to analyze the processes of designation and rewriting in the Scientific Dissemination Text aimed for children from the Semantics of Enunciation, based on the premise that the meaning of statements is inser-

\footnotetext{
* Mestre em Letras/Linguística - Linha de pesquisa Texto e Discurso/UFMA campus Bacabal. E-mail: elyzmello49@gmail.com. Lattes: http://lattes.cnpq.br/5377155130215252

** Mestre em Letras. Universidade Federal do Maranhão, Programa de Pós-graduação em Letras, campus III, Bacabal / Professora do Instituto Federal de Educação - Campus São João dos Patos-MA. E-mail: leonildes.leao@ifma.edu.br. Lattes: http://lattes.cnpq.br/2069644946487302

*** Doutor em Letras (Estudos Linguísticos) Universidade Presbiteriana Mackenzie - UMP. Professor adjunto da UFMA, campus Bacabal. E-mail: paulodasilvalima@yahoo.com.br. Lattes: http://lattes.cnpq. br/0045627183937041
} 
ted in the enunciation event. For this, we took as theoretical basis Guimarães (2009, 2014, 2018), Machado (2019) and Silva (2019). We discussed the proposal taking as a corpus Scientific Dissemination Texts taken from the online version of the magazine Ciência Hoje das Crianças (CHC), in which we analyzed the processes of designation and rewriting and the way they act in the construction of the meanings of the statements. In view of this, we were able to verify that the designation and the rewriting establish relations of meaning in the construction of the texts allowing the interlocutors to participate in the enunciative event through the comprehension of the statements.

Keywords: Enunciation semantics; Designation; Rewriting; Scientific Dissemination.

\section{Introdução}

O funcionamento da língua na sociedade só ocorre com eficácia se o enunciado for compreendido pelos interlocutores, pois se um enunciado chegar ao interlocutor sem significação, não surtirá o efeito pretendido pelo locutor, porque não fará nenhum sentido, pois, para se compreender um enunciado é necessário que as palavras utilizadas sejam de alguma forma, reconhecidas pelo interlocutor ou falante da língua. Para essa compreensão, podemos dizer que a produção desse sentido se dá na materialização dos enunciados no ato enunciativo, que atribui sentido ao real, passando a significar mediante o conhecimento dos interlocutores.

Por isso, a Semântica da Enunciação propõe uma forma de interpretar o texto baseado na semântica e analisa os enunciados, nomes e expressões dentro do próprio ato de enunciar no momento em que acontece a enunciação, dentro de um contexto de produção e interpretação, pois, olhando por esse ângulo, os enunciados passam a fazer mais sentido por estarem inseridos no acontecimento da enunciação. Desse modo, a Semântica da Enunciação busca analisar o texto no interior da semântica, deixando de lado as unidades de análises tradicionais pautadas pelo estruturalismo, passando a seguir pelo viés do discurso, enunciação e pragmática.

Nesse sentido, as unidades de análises propostas pela Semântica da Enunciação são a articulação e reescrituração, que funcionam como dois procedimentos fundamentais na constituição da enunciação. Embora a articulação seja um procedimento de análise da Semântica da Enunciação, neste trabalho nos voltaremos apenas para a reescrituração, que para entendermos seu funcionamento necessitamos também fazer uma abordagem sobre a designação. Dessa maneira, entendemos a designação como a significação de um nome que estabelece relações de sentido com outros nomes e com outras coisas existentes no mundo, cujo significado não seja abstrato nas relações de linguagens. Já a reescrituração consiste no modo de redizer o dito utilizando outros termos linguísticos, de modo que no processo de reescritura não perca a essência do termo reescriturado.

Em vista disso, compreendendo a relevância desta temática, tomamos como questionamento norteador a seguinte pergunta: Como os processos de designação e reescritura atuam para a construção dos sentidos em textos de divulgação científica? Em 
busca de respostas para tal questionamento nos propomos a analisar os processos de designação e reescritura no texto de divulgação científica destinado ao público infantil a partir da Semântica da Enunciação.

Para a discursão proposta nesta pesquisa, tomaremos por base teórica Guimarães (2009, 2014, 2018), Machado (2019) e Silva (2019). Para as análises, tomamos como corpus textos de divulgação científica retirados da versão on-line da revista Ciência Hoje das Crianças (CHC).

Portanto, iniciaremos a discussão com os pressupostos teóricos sobre Semântica da Enunciação, em seguida discorreremos sobre designação e reescritura. Logo após, apresentaremos os procedimentos metodológicos e posteriormente, serão feitas as análises dos seguintes textos: "Nariz para fazer som" e "Etnoconhecimento: saberes que ultrapassam o tempo". Por fim, serão feitas algumas considerações finais. Sendo assim, daremos continuidade discorrendo sobre Semântica da Enunciação.

\section{Semântica da Enunciação}

Os estudos sobre a Semântica da Enunciação surgiram por meio de pesquisas realizadas por Eduardo Guimarães em meados de 1970, em que o autor se voltou para o estudo de "uma semântica que analisa enunciados e expressões no acontecimento da enunciação" (GUIMARÃES, 2018, p.9), tomando por base teórica no campo da enunciação, principalmente, os estudiosos Émile Benveniste e Oswald Ducrot. Mediante o diálogo com a teoria Benvenistiana, o autor estabelece que "a linguagem interessa, antes de tudo, porque ela significa” (GUIMARÃES, 2018, p.7). E por esse motivo, a língua deve ser estudada em seu funcionamento, e os enunciados passam a fazer mais sentido quando inseridos no contexto e ato anunciativo.
Percebendo a necessidade de inserção dos enunciados no contexto no qual é produzido, Guimarães (2018) inseriu a história como um elemento fundamental, sendo também fonte de sentido no processo enunciativo e na produção dos enunciados. Dessa maneira, considerando a história e o espaço no qual os enunciados são produzidos, o autor passa a olhar para o sentido dos enunciados dentro de um contexto de produção, valorizando o acontecimento enunciativo no ato de produção. Dessa forma, o estudo de Guimarães passou a ser considerado como Semântica da Enunciação, conhecida também como Semântica Histórica ou Semântica do Acontecimento.

Tendo em vista que o sentido da língua está em sua significação, o autor supracitado destaca que a significação, especificamente, é o que se apresenta por aquilo que se diz, e isso a caracteriza como algo que ocorre em algum lugar e em determinado momento, e se produz pela enunciação realizada por alguém de alguma fonte de linguagem específica. Com esse raciocínio, pode-se afirmar que a significação dos enunciados ou palavras será produzida na enunciação, e nesse caso, não se pode pensar apenas em um significado literal ou estrutural das palavras e enunciados, mas considerar o que é dito como um conjunto de elementos, que juntos produzem sua própria significação no momento da enunciação.

Diante do pensamento do autor sobre a significação, faz-se necessário dizer que a "a enunciação é o que ocorre quando alguém diz algo, quando um falante de uma língua diz uma sequência que é, de alguma maneira, reconhecida pelos falantes desta língua" (GUIMARÃES, 2018, p.14), e por essa razão é que a significação se dá no acontecimento da língua. Portanto, para Guimarães (2018, p.13), a Semântica "tem como objeto o es- 
tudo da significação tomada como produzida pela prática dos falantes de dizer algo em uma língua". Assim sendo, a Semântica da enunciação "é a disciplina que analisa os sentidos dos enunciados enquanto enunciados que integram textos nos acontecimentos que os produzem" (GUIMARÃES, 2018, p. 22). Essa integração no ato de produção, consequentemente, fará mais sentido para os interlocutores.

0 autor acrescenta que o acontecimento enunciativo se produz pelo funcionamento da língua nos espaços enunciativos, e, por isso, pode-se afirmar que a produção de sentido dos enunciados no acontecimento da enunciação é fundamentada historicamente e que pode variar de sentido mediante o espaço e o tempo no qual o locutor está inserido, levando em conta as condições de produção que se apresentam no acontecimento da enunciação.

Para o desenvolvimento das análises no campo da Semântica da Enunciação, Guimarães (2018) foca nos processos de articulação e reescrituração dos enunciados. A relação entre a articulação e reescritura nos enunciados, segundo Silva (2019), é decisiva para o processo de descrição e análise semântica do enunciado, pois o processo da articulação está voltado para a construção de sentidos ligado à estrutura e coesão do texto, e o modo da reescrituração volta-se para o significado das palavras dentro do texto e contexto no qual está sendo utilizado. Com isso, a relação enunciativa inseridas no texto, o significado do enunciado passa a ter mais sentido para os interlocutores, uma vez que o interlocutor pode fazer sua própria leitura e análises da significação do enunciado, mediante o campo semântico que ele tem conhecimento.

Mesmo se tratando de dois modos de análises na Semântica da Enunciação, neste trabalho tomaremos por modo de análise a reescrituração, a qual detalharemos no próximo tópico, descrevendo o modo de funcionamento da designação e reescritura nos enunciados.

\section{Designação e reescritura}

No processo de construção de um enunciado o sentido de um nome vai se dando na medida em que se relaciona com outros nomes formando um significado como um todo. Com isso, o nome deixa de ser compreendido apenas no significado restrito passando a unir-se com outras palavras, nomes ou termos que também significam em sua relação com mundo para, assim, construir um significado completo. Essa relação entre as palavras na construção do enunciado acontece pela designação das palavras, pois:

A designação é o sentido de um nome que estabelece a relação desse nome com as coisas tomadas como existentes, mas esta relação não é referencial. Trata-se de um processo pelo qual os nomes identificam aquilo sobre o que falam. A linguagem, nessa medida, produz uma 'partilha do real'. A designação identifica o existente (físico ou não) de algum modo, e essa é a relação que tem com ele, a qual, inclusive, possibilita que se faça referência a coisas particulares em situações particulares (GUIMARÃES, 2014, p.60-61).

Nessa perspectiva, o sentido de um nome torna-se completo pela existência de outros nomes que identificam no mundo as coisas sobre as quais se diz, e nisso acontece uma interação do real ao que está sendo designado. E tomando a designação na concepção enunciativa, é possível dizer que o sentido deve "ser tomado pela linguagem em virtude do que uma expressão significa num enunciado específico de um texto específico" (GUIMARÃES, 2018, p.153). Nesse raciocínio, o conjunto de palavras que compõem um texto se dá pela escolha lexical que ve- 
nha a fazer combinações de sentido para significar como um todo, e, dependendo do texto ao qual essas palavras pertencem, elas farão sentido mediante o enunciado produzido, mas sem perder de vista a função à qual é designada.

No que se refere à reescrituração, segundo Guimarães (2009) diz que a reescrituração consiste em se redizer o que já foi dito. 0 autor reitera que:

A reescrituração é o modo de relação pelo qual a enunciação rediz o que já foi dito. Há reescrituração quando um elemento $\mathrm{Y}$ de um texto (uma palavra, uma expressão, por exemplo) retoma um outro elemento $X$ do texto. Neste caso Y reescritura X. Este modo de relação enunciativa leva a interpretar uma forma como diferente de si. 0 elemento que reescritura atribui (predica) sentido ao reescriturado. Uma característica fundamental da reescrituração é que ela não se caracteriza pelas relações segmentais, ou de contiguidade, própria dos modos de articulação (GUIMARÃES, 2018, p.85).

Diante da definição do autor, pode-se notar que o processo de reescrituração permite ao locutor utilizar recursos linguísticos disponíveis na língua para refazer, redizer, reescrever o que foi dito em outros termos, sem perder de vista a essência do que está sendo dito, fazendo uma adequação de um nome a ser reescriturado em um enunciado de modo que não perca seu significado passando pelo processo de reescrituração.

Nesse raciocínio, a reescrituração, segundo Guimarães (2018) se dá pelos modos de repetição, substituição, elipse, expansão e condensação. Ainda segundo o autor, a repetição se dá no fato de redizer, a substituição pode se dar pela anáfora e por outros modos. Quanto às diversas relações de sentido produzidas pelas reescriturações, temos a sinonímia, especificação, desenvolvimento, globalização/totalização, definição.
Guimarães (2018) define esses modos de reescrituração da seguinte forma: a) a reescrituração (por sinonímia) apresenta uma palavra ou expressão como tendo o mesmo sentido que a outra à qual se liga, e pode ser produzida liga de repetições; b) a reescrituração por especificação atribui sentido ao reescriturado pela expressão que o reescritura; c) desenvolvimento - uma relação de desenvolvimento pode ser vista pela expansão na escrituração; d) globalização ou totalização - corresponde à reescrituração por condensação; e) definição - uma a ser considerada especialmente "é a que estabelece uma relação de definição entre a reescrituração e o reescriturado", (GUIMARÃES, 2018, p.91), considerada também como reescrituração por expansão.

Diante disso, podemos observar que a reescrituração pode ser feita de vários modos, sendo utilizada de acordo com a construção do enunciado e a necessidade do elemento a ser reescriturado. Diante dos pontos teóricos elencados sobre designação e reescritura, passemos aos procedimentos metodológicos.

\section{Procedimentos metodológicos}

Para esta pesquisa traçamos por objetivo analisar os processos de designação e reescritura no texto de divulgação científica destinado ao público infantil, em uma perspectiva da Semântica Enunciativa, partindo da ideia de que o sentido dos enunciados está inserido no acontecimento da enunciação. E por isso, a designação e a reescritura presentes nos enunciados tornam-se elementos importantes no processo de construção dos textos, levando em conta o contexto enunciativo a qual os enunciados são produzidos.

A pesquisa foi ancorada teoricamente em Guimarães (2009, 2014, 2018), Macha- 
do (2019) e Silva (2019), mostrando por meio da Semântica da Enunciação que os textos ganham mais sentido quando estudados no interior da semântica e inseridos no processo de enunciação. Tomamos por corpus para as análises dois textos: "Nariz para fazer som" e "Etnoconhecimento: saberes que ultrapassam o tempo", da seção artigo, edição 293 e 294 do ano de 2019. Ambos os textos são de divulgação científica e foram selecionados das versões on-line da revista Ciência Hoje das Crianças (CHC), cuja escolha se deu pelo fato de serem textos atuais e relevantes para a sociedade, especialmente porque abordam temas interessante para o público infantil, que apesar de serem de ordem científica, não se apresentam de forma complexa, além disso, possuem os elementos necessários à análise que propomos. Portanto, cientes do conhecimento teórico que embasa esta pesquisa, passemos então às análises dos textos.

\section{Breve análise de Textos de Divulgação Científica}

Prosseguiremos, neste tópico, analisando, à luz da Semântica da Enunciação, os processos de designação e reescritura no texto de divulgação científica destinado ao público infantil. Para isso, escolhemos dois textos retirados das edições on-line da revista Ciência Hoje das Crianças (CHC), com temas e conteúdos variados, no intuito de ampliar o conhecimento científico dos interlocutores e de mostrar como os processos de designação e reescritura colaboram na construção do texto para se tornar mais compreensível, levando em conta a significação e o processo enunciativo do texto em seu contexto. Desse modo, daremos início à análise do primeiro texto.

Texto 1- Nariz para fazer som!

\begin{tabular}{|c|l|}
\hline 1 & Você recebeu o convite para assistir à apresentação de uma grande orquestra. O teatro está \\
2 & lotado e o seu ingresso é para - uau! - a primeira fila! Você está muito perto dos músicos. \\
3 & Pode ver violinos, violoncelos, contrabaixos, harpas, flautas, clarinetes, trompetes, tubas. O \\
4 & som é puro encantamento. Você aproveita cada segundo e sai de lá com a certeza de que uma \\
5 & obra musical é resultado da união de diferentes fontes sonoras, traduzindo a emoção de \\
6 & um compositor. \\
7 & Continue viajando na imaginação e tente imaginar que você recebeu um convite para ver \\
8 & outra orquestra. Dessa vez não será no teatro, mas no fundo do mar! Os músicos são nada \\
9 & mais, nada menos do que os golfinhos! Sim, esses animais marinhos evoluíram um instru- \\
10 & mento capaz de compor combinações de sons indispensáveis para se comunicarem com o \\
11 & seu grupo, navegar e caçar. Que instrumento é esse? O nariz dos golfinhos! \\
\hline
\end{tabular}

Fonte: CHC, Seção Artigo, Edição 294, 2019. (Grifos do autor).

No Texto 1, é abordado um conteúdo que desperta a curiosidade do interlocutor por meio

de uma comparação feita entre instrumentos musicais e músicos de uma orquestra com o barulho emitido pelo nariz dos golfinhos. No título do texto, "Nariz para fazer som!", podemos notar o modo de designação da palavra "nariz" que é um membro do corpo, que para se tornar compreensível no enunciado é feita a reescritura, fazendo uma ligação das palavras "nariz e som" de modo que dê sentido ao título provocando curiosidade no interlocutor, incitando-o à leitura do texto por completo, pois apenas pelo tí- 
tulo o interlocutor não tem como saber de imediato do que de fato se trata o texto.

No primeiro parágrafo, podemos observar que o sentido do texto é compreendido pelo fato de as palavras serem usadas em sua forma própria de designação. Nas linhas 1, 2 e 3 as palavras "orquestra", "teatro", "músicos" são usadas no seu sentido literal, pois, segundo o dicionário online Michaelis (2020), orquestra é o conjunto de instrumentistas que executam peças musicais e sinfônicas normalmente sob regência de um maestro, "teatro" lugar destinado à representações de obras (dramáticas, comédias, romance e etc...) e outros espetáculos públicos, e "músicos" são profissionais que exercem atividades relacionadas à música. Dessa forma, essas palavras se tornam compreensíveis no enunciado pela sua significação e passam a fazer sentido mediante ao campo semântico do interlocutor.

No segundo parágrafo, linha 7, o enunciador usa do verbo "continue" no imperativo e convoca o enunciatário a permanecer fazendo um percurso pelo conteúdo a qual está abordando quando fala "continue viajando na imaginação". Essa expressão é utilizada no intuito de fazer com que o enunciatário já conhecendo o enunciado anterior, possa adentrar no enunciado posterior a fim de levar o interlocutor a construir sua própria compreensão do enunciado como um todo. Nessa transição do primeiro para o segundo parágrafos, vale ressaltar que o espaço de enunciação muda de um parágrafo para o outro, e consequentemente, o sentido.

Desse modo, podemos perceber que a palavra "orquestra", na linha 8, está presente no segundo parágrafo, mas na construção desse enunciado ela se apresenta não mais em sua significação, como no primeiro parágrafo. Nesse caso acontece o processo de reescrituração, que segundo Machado (2019) é o modo em que uma palavra é redita por outras palavras e como isso produz outros sentidos no acontecimento enunciativo, estabelecendo uma relação do presente da enunciação com o passado, com o memorável que é recortado. Nesse sentido, a palavra “orquestra", linha 7 , está relacionada a uma orquestra de golfinhos, que passa a ter significado dentro do contexto semântico-enunciativo no qual está inserido. Esse mesmo processo de reescrituração ocorre com as palavras "teatro" e "músicos" na linha 8.

Ainda na linha 8 pode-se observar no enunciado "Dessa vez não será no teatro, mas no fundo do mar" que a palavra "teatro", para obter sentido no processo de reescrituração está semanticamente ligado ao termo "fundo do mar". Nesse caso, há a reescrituração pelo modo de expansão, pois expande o sentido da palavra teatro ampliando a visão do enunciatário, situando-o no espaço enunciativo ao qual o enunciador está se referindo, o "fundo do mar". Conforme Guimarães (2009), aqui, essa ligação entre as expressões é um modo de ampliar o que está dito no termo teatro.

Esse mesmo processo de reescrituração pelo modo de expansão ocorre no enunciado "Os músicos são nada mais, nada menos do que os golfinhos!" nas linhas 8 e 9, ao esclarecer para o enunciatário que os músicos são os golfinhos, e não os musicistas aos quais a palavra se refere no primeiro parágrafo. Nesse caso, "golfinhos" aparece no texto com significado próprio de sua designação e ao mesmo tempo reescritura a palavra "músicos" da linha 3 do primeiro parágrafo.

Segundo Guimarães (2009, p. 54), "uma expressão linguística reporta-se a uma outra por algum procedimento que as relaciona no texto integrado pelos enunciados em que ambas estão". Esse procedimento se dá pela 
interpretação de uma forma reescriturada diferente de si, em virtude de outra reescrituração. Nesse sentido, a reescrituração de uma palavra, termo ou expressão linguística é uma forma de redizer o dito usando outros termos que se ligam ao dito em um dado espaço semântico e enunciativo abrindo espaço para uma nova interpretação.

Na linha 9, a expressão "esses animais marinhos" reescritura a palavra "golfinhos", dito no enunciado anterior, de modo que o operador "esses", evita a repetição, e "animais marinhos" expande o significado da palavra golfinhos. Dando continuidade ao sentido do enunciado, a palavra "instrumento", linha 10 , reescritura pelo modo de condensação todos os instrumentos musicais citados nas linhas 3 e 4 do primeiro parágrafo: "violinos, violoncelos, contrabaixos, harpas, flautas, clarinetes, trompetes, tubas". Esse modo de reescritura por condensação resume informações de modo que não se perca o sentido do enunciado, mas que apenas na palavra instrumento fiquem implícitas informações que podem ou não ser expostas sem prejudicar o sentido do enunciado.

Vale lembrar que, nesse segundo parágrafo, o campo semântico da palavra instrumento já está relacionado ao nariz do golfinho, explícito pelo enunciado "instrumento capaz de compor combinações de sons", linha 10. Nesse mesmo enunciado, além da palavra instrumento há também a reescrituração "compor combinações de sons" que reescritura "união de diferentes fontes sonoras", na linha 5, no primeiro parágrafo. Ainda no segundo parágrafo, podemos perceber que as palavras "navegar e caçar" não apresentam sua própria significação, e mesmo não estando explícitas em outras partes do enunciado, o sentido é reescriturado pelo contexto semântico e espaço enunciativo do enunciado como um todo. Vejamos agora a análise do segundo texto.

Texto 2 - Etnoconhecimento: saberes que ultrapassam o tempo

\begin{tabular}{|c|l|}
\hline 1 & Vivemos na era da informação. Basta acionarmos o controle remoto da TV, ligarmos o com- \\
2 & putador ou darmos dois cliques no celular que passamos a ter acesso aos mais diferentes \\
3 & conhecimentos. Tudo em sintonia com a tecnologia. Até para distrair ou relaxar, a gente se \\
4 & acostumou a usar a tecnologia. É videogame, série, novela...Tem sempre uma inovação tec- \\
5 & nológica no meio da nossa diversão. Mas fazer o quê, né? O mundo inteiro está assim... \\
6 & Será mesmo? \\
7 & Pelo mundo todo existem povos que podem até ter alguma conexão tecnológica, mas que \\
8 & consideram muito mais importante o aprendizado com a natureza e com os mais experien- \\
9 & tes. Esse conhecimento, que é passado de uma geração para outra, também pode ser compar- \\
10 & tilhado com pessoas de fora daquele grupo, seja desinteressadamente ou, por exemplo, com \\
11 & o propósito de conservar o ambiente em que vivemos. \\
12 & Etno vem do grego ethnos, que significa 'identidade de um povo'. Etnoconhecimento é um \\
13 & termo criado para dar conta de tudo aquilo que alguns povos têm e podem compartilhar, in- \\
14 & cluindo crenças, tradições, modo de fazer ou de produzir alguma coisa. \\
15 & Etnoconhecimento se refere especialmente ao que os indígenas, os quilombolas, os pes- \\
16 & cadores e outras comunidades tradicionais ou locais e que buscam viver em sintonia com o \\
17 & ambiente e seus recursos naturais, têm a ensinar para quem está bem longe dessa realidade! \\
\hline
\end{tabular}

Fonte: CHC, Seção Artigo, Edição 293, 2019. (Grifos do autor). 
0 texto "Etnoconhecimento: saberes que ultrapassam o tempo" faz um percurso na história da evolução de conhecimentos tecnológicos e saberes advindos de povos, costumes e culturas que ajudaram na evolução da ciência. Com isso, o primeiro parágrafo faz alusão à tecnologia, afirmando que vivemos na era da informação e que a humanidade está cercada e imersa na tecnologia. Ao estar inserido no meio tecnológico, o interlocutor compreenderá o sentido do enunciado, pois todas as palavras e termos utilizados pertencem ao campo semântico dos interlocutores, isso faz com que haja entendimento do texto em sua essência.

No entanto, nas linhas 5 e 6, duas interrogações são lançadas ao interlocutor, "Mas fazer o que, né? 0 mundo inteiro está assim... Será mesmo?". Esses questionamentos lançados funcionam como forma de levar o interlocutor a fazer uma reflexão sobre as tecnologias mencionadas no enunciado anterior e analisar se, de fato, apenas essas tecnologias é que são importantes, ou se antes dessas tecnologias existiam outras formas de conhecimento que também colaboraram com o que hoje podemos conceituar ou chamar de tecnologia. Nota-se que, no primeiro parágrafo, as formas de designação aparecem dando sentido ao enunciado pela sua própria significação.

Ainda na linha 5, o termo "mundo inteiro" reescritura de modo condensado, pois, de acordo com Guimarães (2009), aqui o "mundo inteiro" condensa toda a informação anterior, dando a entender que a humanidade inteira está imersa na tecnologia. Nesse sentido, a reescrituração ocorre quando uma expressão de apenas duas palavras abarca todo o sentido que o locutor quer transmitir ao interlocutor, sem precisar citar nomes de cidades, países e/ou con- tinentes para se referir à humanidade como um todo. Esse mesmo caso se repete na linha 7 por meio da expressão "mundo todo", no início do segundo parágrafo.

O segundo parágrafo, na tentativa de responder aos questionamentos feitos no primeiro parágrafo, coloca em questão um outro tipo de conhecimento que se opõe ao conhecimento tecnológico expresso no enunciado "o aprendizado com a natureza e com os mais experientes", nas linhas 8 e 9. $\mathrm{Na}$ continuidade do parágrafo esses termos são reescriturados por "Esse conhecimento", em que "esse", além de ser um operador que colabora na articulação no enunciado, juntamente com a palavra "conhecimento" reescritura de modo condensado "o aprendizado com a natureza e com os mais experientes", como já citamos.

Prosseguindo com análise e compreensão do enunciado, no terceiro parágrafo podemos notar a reescrituração por definição em "Etno vem do grego ethnos", linha 12, pois ao mesmo tempo em que define "ethnos" como "Identidade de um povo" especifica e expande o sentido de ethnos. Na sequência, na linha 15, "Etnoconhecimento" reescritura "identidade de um povo" de modo condensado e ao mesmo tempo é reescriturado pelo modo de especificação e expansão por "é um termo criado para dar conta de tudo aquilo que alguns povos têm e podem compartilhar, incluindo crenças, tradições, modo de fazer ou de produzir alguma coisa" nas linhas 13 e 14.

Nesse sentido, de acordo com Guimarães (2009, p. 54), "neste caso a reescrituração claramente determina o reescriturado pela expressão que o reescritura". Desse modo, o termo reescriturado "Etnoconhecimento" será determinado pela reescritura expandindo, explicando e redizendo em outros termos o que já foi dito no enunciado dentro 
do espaço semântico-enunciativo do acontecimento da enunciação.

0 terceiro parágrafo finaliza o texto ampliando o conhecimento do interlocutor explicando e justificando as afirmações e os questionamentos sobre a tecnologia presentes no primeiro parágrafo. Tais justificativas se dão ao afirmar que "os indígenas, os quilombolas, os pescadores e outras comunidades tradicionais ou locais e que buscam viver em sintonia com o ambiente e seus recursos naturais, têm a ensinar para quem está bem longe dessa realidade". Após o percurso das análises, passemos para as considerações finais.

\section{Considerações Finais}

0 intuito desta pesquisa foi analisar os processos de designação e reescritura em textos de divulgação científica destinados ao público infantil, em uma perspectiva Semântica Enunciativa. Para isso, fizemos um breve percurso sobre a Semântica da Enunciação, bem como sobre os modos de designação e reescritura, embasados em Guimarães (2009, 2014, 2018), Machado (2019) e Silva (2019) tomados por suporte teórico para fundamentar as análises.

Após tomar conhecimento dos pressupostos teóricos, podemos afirmar que estudar a língua em seu funcionamento faz mais sentido, e ao inserir os enunciados no acontecimento enunciativo, o texto tornase compreensível não apenas pela sua significação, mas passa a ganhar mais sentido também pelo contexto e espaço enunciativo no qual está sendo produzido. Desse modo, na análise do corpus, pudemos constatar que os processos de designação e reescritura são essenciais na construção dos sentidos em textos de divulgação científica, pois além de colaborarem na coesão dos textos, ajudam também no processo de compreen- são e interpretação dos enunciados, fazendo com que o locutor compreenda e interprete o enunciado mediante o campo semântico por ele adquirido.

Por fim, entendemos que ler, compreender e interpretar um texto na perspectiva Semântica Enunciativa possibilita maior compreensão aos interlocutores, e que os modos de designação e reescritura nos enunciados são processos que ajudam na construção dos sentidos dos textos, possibilitando uma interpretação que vai além da significação, perpassando pela reconstrução de nomes, termos ou sentenças de modo que se tornem mais compreensível ao interlocutor. Portanto, torna-se premente mais pesquisas relacionadas aos modos de designação e reescritura no contexto da Semântica Enunciativa, uma vez que são elementos que colaboram no processo de construção de sentido dos enunciados.

\section{Referências}

ARTIGO. In: REVISTA Ciência Hoje das Crianças. Disponível em: <www.chc.org.br>. Acesso em: 10 set. 2020 .

GUIMARÃES, E. Enumeração, funcionamento enunciativo e sentido. Cad.Est.Ling., Campinas, 51(1): 49-68, Jan/Jun. 2009. Disponível em: <https://periodicos.sbu.unicamp.br/ojs/ index.php/cel/article/view/8637219>. Acesso em: 04 set. 2020 .

GUIMARÃES, Eduardo. Espaço de enunciação, Cena enunciativa, Designação. Fragmentum (UFSM), v. 40, p. 49-76, 2014.

GUIMARÃES, E Semântica: enunciação e sentido. Campinas: Pontes Editores, 2018

MACHADO, Carolina de Paula. Contribuições da semântica da enunciação para a

análise de texto. Traços de Linguagem, Cáceres, v. 3, n. 2, p. 28-41, 2019. Disponível em: <https://periodicos.unemat.br/index.php/tracos/ article/view/4355>. Acesso em: 04 set. 2020.

MICHAELIS, Dicionário Brasileiro da Língua 
Portuguesa. Disponível em https://michaelis. uol.com.br/moderno-portugues/busca/portuguesbrasileiro/m\%C3\%BAsico/. Acesso em 03 de setembro de 2020.

SILVA, Claudiene Diniz da. Glossário de Semântica da Enunciação. UFMG. Relatório de Está- gio pós-doutoral, 2019. Disponível em: <http:// www.letras.ufmg.br/nucleos/enunciar/>. Acesso em: 07 set. 2020.

Recebido em : 15/04/2021 Aprovado em: 13/08/2021

(c) Esta obra está licenciada com uma Licença Creative Commons Atribuição 4.0 Internacional. 